\title{
CULTURA DA SEGURANÇA NA ÁREA DA SAÚDE
}

\author{
MABEL DUARTE ALVES GOMIDES 1 ; MICHELLY DE MELO ALVES2; REILA \\ SILVA PEREIRA AIRES3; AMANDA OLIVEIRA SOARES MONTEIRO \\ SILVEIRA4; EDNÓLIA GOMES VARJÃO FERNANDES5; GERALDO \\ SADOYAMA6.
}

\section{Resumo}

A segurança do paciente despertou muita preocupação e alerta ao mundo, após evidências científicas de elevados índices de mortalidade referentes a falhas durante a prestação de cuidados relacionados à saúde. A complexidade do sistema que envolve o cuidado na saúde, principalmente nos hospitais, exige uma gestão de saúde especializada e voltada para a qualidade e segurança do paciente. Observouse que a cultura da segurança reflete, essencialmente, as atitudes dos gerentes e trabalhadores e os valores relacionados com a gestão de risco e da segurança. Até recentemente, os estudos sobre a cultura da segurança estavam focados principalmente na exploração das deficiências presentes na organização, comunicação e habilidades pessoais, com poucos estudos demostrando a relação entre as atitudes de segurança e desempenho da equipe ou o entendimento de valores, crenças e normas de uma organização, ou ainda, como as atitudes e comportamentos relacionados à segurança do paciente são suportados, recompensados e esperados. Entre as peculiaridades da cultura de segurança, está a necessidade de se comprometer com a discussão e o aprendizado a partir dos erros, vistos que são inevitáveis. Portanto, é imprescindível identificar pró-ativamente as ameaças latentes nas informações $e$ análises dos eventos adversos, incorporando regras não punitivas e medidas de identificação de áreas com maior ou menor necessidade de melhoria da consciência de segurança do paciente. $O$ objetivo deste estudo foi fazer uma revisão sobre cultura de segurança relacionado à assistência à saúde.

Palavras-chave: Cultura, Gestão de Segurança, Segurança

\footnotetext{
1 Médica Dermatologista e Intensivista do HC-UFU/Uberlândia, Mestrado Profissional em Gestão Organizacional - Regional Catalão/UFG. E- mail: mabel@dermaclinicagoias.com.br

2 Enfermeira, Professora do curso de Enfermagem UFG/RC, Mestranda do Programa de Mestrado Profissional em Gestão Organizacional - Regional Catalão/UFG. E- mail: michellymeloa@hotmail.com

${ }^{3}$ Médica Intensivista e Gastroenterologista, Mestranda do Programa de Mestrado Profissional em Gestão Organizacional - Regional Catalão/UFG. E- mail: reilasp@gmail.com

4 Médica Endocrinologista, Mestranda do Programa de Mestrado Profissional em Gestão Organizacional - Regional Catalão/UFG. E- mail: amanda.osm@bol.com.br

${ }^{5}$ Enfermeira, Mestranda do Programa de Mestrado Profissional em Gestão Organizacional - Regional Catalão/UFG. E- mail: ednoliavariao@yahoo.com

${ }^{6}$ Biólogo, Professor do Mestrado Profissional em Gestão Organizacional - Regional Catalão/UFG. Email: sadoyama@ufg.br
} 


\section{INTRODUÇÃO}

A cultura de segurança do paciente é definida como um subconjunto da cultura organizacional, que se refere especificamente aos valores e crenças sobre a segurança dos doentes nas organizações de saúde (FENG et al., 2008). Em essência, a cultura pode ser expressa como a forma como fazemos as coisas em torno da nossa unidade de trabalho (PRONOVOST; SEXTON, 2005).

A segurança dos pacientes tem despertado muita preocupação nas organizações mundiais, em virtude de evidências científicas demonstrando falhas nos cuidados de saúde associadas a elevadas taxas de mortalidade.

Em 1999, o IOM publicou o relatório intitulado "Errar é Humano" (To err is human), apontando para gravidade dos problemas de segurança relacionados aos cuidados de saúde, sugerindo o tema para a pauta da Organização Mundial da Saúde e para as políticas de saúde de diversos países, além de estabelecer uma estratégia global do sistema na prevenção dos erros nas organizações de saúde. Esse relatório foi baseado na publicação de artigos que demonstraram que cerca de 44.000 a 98.000 pessoas morriam todos os anos nos E.U.A., vítimas de iatrogenias médicas e que 7.000 destes casos estavam relacionados aos erros com medicação (KOHN; CORRIGAN; DONALDSON, 1999).

Contudo, a informação sobre a segurança do paciente desempenhou um papel importante na criação da Federal Quality Interagency Coordination Task Force, que incluiu representantes da Agência de Investigação de Qualidade e Saúde (Agency for Healthcare Research and Quality- $A H R Q$ ). Essa força-tarefa destacou o efeito dos cuidados de saúde e condições de trabalho na segurança do paciente e concluiu que as intervenções destinadas a melhorar a saúde e o local de trabalho também melhorariam a qualidade geral dos cuidados de saúde (AHRQ, 2008).

Em seguida, em 2001, o IOM publicou o relatório "Cruzando o Abismo da Qualidade" (Crossing the quality chasm) com um foco mais amplo no sistema de saúde, definindo seis domínios para caracterizar o desempenho do sistema de saúde, com destaque para o domínio da segurança do paciente. São eles: segurança, efetividade, foco no paciente, otimização, eficiência e equidade (VINCENT, 2010; IOM, 2001).

Em 2004, a Organização Mundial de Saúde lançou o programa da Aliança Mundial para a Segurança do Paciente, a fim de incentivar e divulgar, em diferentes países, as diretrizes e estratégias que garantem a segurança do paciente (WHO, 2004). Por isso, houve avanços nas pesquisas sobre cultura de segurança, buscando analisar o contexto nas instituições de saúde por meio da aplicação de instrumentos de mensuração do clima de segurança (GERSHON et al., 2004).

Em discussões recentes, a segurança do paciente tem sido considerada uma dimensão da qualidade em saúde, que deve ser garantida ao paciente por meio de uma cultura de atitudes segura, construída e aceita por todos os profissionais envolvidos. A segurança do paciente apresenta como definição o aumento da probabilidade de desfechos desejados, ou seja, a redução a um mínimo aceitável de danos evitáveis ao paciente durante o processo de assistência à saúde $(\mathrm{KOHN}$; CORRIGAN; DONALDSON, 1999; WHO, 2009; ANVISA, 2013).

Entre as peculiaridades da cultura de segurança, está a necessidade de se comprometer com a discussão e o aprendizado a partir dos erros, vistos que são inevitáveis. Portanto, é imprescindível identificar pró-ativamente as ameaças latentes nas informações e análises dos eventos adversos, incorporando regras não punitivas (BOGNÁR et al., 2008) e medidas de identificação de áreas com maior ou 
menor necessidade de melhoria da consciência de segurança do paciente (NIEVA; SORRA, 2003).

Alguns autores acreditam que a qualidade e a segurança relacionadas à assistência à saúde devem ser analisadas visando a uma compreensão do sistema e das circunstâncias em que ocorrem os erros e eventos adversos. (KOHN; CORRIGAN; DONALDSON, 1999; REASON, 1995; REASON, 1997; VINCENT; TAYLOR-ADAMS; STANHOPE, 1998). Portanto, a segurança do paciente depende de atuações amplas e esforços complexos nos vários segmentos de uma organização, promovendo a melhoria do ambiente e gerenciamento de riscos para uma boa prática das atividades diárias, detecção e controle nas áreas de maior impacto nos problemas de segurança, aproveitamento adequado da tecnologia e capacitação dos profissionais (WOLFE, 2001; NIEVA; SORRA, 2003; VINCENT, 2003; WIEGMANN, 2004; PITTET; DONALDSON, 2005; HUANG, 2010; TEIXEIRA; CASSIANI, 2010; WACHTER, 2010, ANVISA 2013, BASSUNI; BAYOUMI, 2015).

Mesmo sendo a segurança do paciente fundamental para a qualidade da saúde, as atenções estão centradas sobre a cultura de segurança do paciente de uma organização e seu impacto sobre os resultados (COLLA et al., 2005; HUANG et al., 2010). Portanto, uma cultura de segurança eficiente parece ser a condição essencial para segurança do paciente no intra-hospitalar, reduzindo o risco de eventos adversos (KLINE et al., 2008).

Desse modo, evidencia-se a necessidade de métodos para a mensuração da cultura de segurança, a exemplo de escalas e questionários (GERSHON et al., 2004). Existe uma diversidade de questionários disponíveis que permitem avaliar a cultura de segurança nas instituições de saúde, seja em unidades hospitalares ou de atenção à saúde específica (COLLA, 2005).

As instituições de cuidados de saúde estão num contexto de elevado risco de mortalidade e morbidade, especialmente nas UTI (COLLA, 2005). Em resposta a esta declaração, o IOM (1999) apontou a necessidade de melhorar a cultura de segurança dos pacientes nas organizações de saúde (KOHN; CORRIGAN; DONALDSON, 1999).

Em consequência disso, a avaliação da cultura de segurança precisa ter a finalidade de proporcionar uma compreensão básica de percepção profissional de saúde e atitudes relacionadas com a segurança nas instituições de cuidados, podendo ser usadas como ferramentas para identificar áreas mais problemáticas relacionadas com a análise de segurança, através de programas de segurança de saúde, que aumentem a conscientização sobre o papel da cultura na promoção de um ambiente seguro para os pacientes (NIEVA; SORRA, 2003). Conforme considerações de outros autores, considera-se que as atitudes profissionais, ações e comportamentos são fatores importantes na manutenção da qualidade do serviço e segurança do paciente (PRONOVOST et al., 2006).

Portanto, existem várias razões para avaliar a cultura de segurança, como: identificar as melhorias, aumentar a conscientização sobre a segurança do paciente, avaliar as intervenções e programas de segurança, avaliar as mudanças ao longo do tempo, criar uma referência de segurança e requisito de segurança completa, podendo essas razões serem vistas como fator isolado ou em combinação (NIEVA; SORRA, 2003; SCOTT et al, 2006).

Em síntese, a sistematização na qualidade da saúde para segurança dos pacientes enfrenta desafios globais na sua implantação e apresenta uma necessidade que vai além do seu custo em vidas humanas, como: desconforto físico e psicológico, produtividade do trabalhador perdida, elevação no tempo e custo da 
internação hospitalar (WOLFE, 2001; IOM, 2001; NIEVA; SORRA, 2003).

\section{DESENVOLVIMENTO}

\subsection{Cultura de Segurança}

Na literatura, o termo cultura de segurança foi utilizado pela primeira vez pelo Grupo Consultivo Internacional em Segurança Nuclear (INSAG) ao publicar o relatório sobre o acidente nuclear de Chernobyl em 1986. A Agência Internacional de Energia Atômica (IAEA, 1991) definiu, pela primeira vez, o termo cultura de segurança como o reflexo das atitudes, crenças, percepções e valores que os funcionários compartilham em relação à segurança (COX; COX, 1991).

Aprimorou-se uma definição global de sobre cultura de segurança, a partir dos pontos em comuns entre os vários conceitos presentes na literatura, sendo: ...a cultura de segurança é o valor duradouro, prioridade concedida ao trabalhador e segurança pública por todos, em todos os grupos e em todos os níveis de uma organização. Isso se refere à medida em que os indivíduos e grupos se comprometem com a responsabilidade pessoal, agindo para preservar, melhorar e comunicar as preocupações de segurança, e se esforçam ativamente para aprender, adaptar e modificar (tanto individual e organizacional) comportamentos com base nas lições aprendidas com os erros; para serem recompensados de forma consistente com esses valores (WIEGMANN et al., 2002).

Com base na definição de COOPER (2000), a cultura de segurança é vista como o resultado das interações dinâmicas e foram analisadas em três aspectos: as atitudes e percepções, aspectos subjetivos de como as pessoas sentem a organização e estão relacionadas com o indivíduo; os comportamentos e as ações, afazeres das pessoas na organização e relacionadas ao trabalho; e o Sistema de Gestão de Segurança do Trabalho, constituído pelas políticas, procedimentos, sistemas de controle, fluxo de informações, e relacionados à organização.

Para IAEA (1991) a cultura de segurança apresenta componentes tangíveis que são indicadores de segurança como o comprometimento dos gerentes e a organização e as intangíveis capazes de influenciar as anteriores como as atitudes e percepções dos empregados em todos os níveis da organização.

\subsection{Cultura de Segurança na Área da Saúde}

As organizações de saúde têm se conscientizado, cada vez mais, da importância de transformar-se em cultura organizacional para melhorar a segurança do paciente. De fato, quando se cria e estabelece a cultura da segurança do paciente entre os seus profissionais a instituição consegue obter resultados positivos na segurança do paciente. Portanto, promover a cultura de segurança tornou-se um dos pilares do movimento de segurança do paciente (NIEVA; SORRA, 2003).

A cultura de segurança é definida como o produto, individual e em grupo, dos princípios entre comportamentos, atitudes, percepções e competências, determinada pelo comprometimento, estilo e capacidade da gestão de uma organização de segurança e saúde (SORRA; NIEVA, 2004).

No Brasil, a cultura de segurança é definida, segundo a RDC $n^{\circ}$. 36/2013, como conjunto de valores, atitudes, competências e comportamentos que determinam o comprometimento com a gestão da saúde e da segurança, 
substituindo a culpa e a punição pela oportunidade de aprender com as falhas e melhorar a atenção à saúde (ANVISA, 2013).

Vários são os fatores que influenciam a prática clínica, entre eles: organizacionais como clima de segurança e a moral, o ambiente de trabalho como os níveis de pessoal e apoio administrativo, a equipe como o trabalho em equipe e supervisão, e a questão pessoal como o excesso de confiança e ser excessivamente autoconfiante (VINCENT; TAYLOR-ADAMS; STANHOPE, 1998).

É importante ressaltar que a partir do acidente da Usina Nuclear de Chernobyl (1986), houve a mobilização do Institute of Medicine (IOM, 2001), OMS e Políticas de saúde de diversos países, que propiciou um novo olhar sobre a melhoria do cuidado de saúde, voltado para o erro humano, os acidentes e sua prevenção (VINCENT, 2010).

A segurança do paciente corresponde a processos assistenciais com redução ao mínimo aceitável do risco de dano desnecessário associado ao cuidado de saúde, e com o melhor desempenho das práticas, atingindo resultados satisfatórios para os pacientes (RUNCIMAN et al., 2009; ZAMBON; DAUD-GALLOTTI; NOVAES, 2010).

As falhas de segurança dos pacientes, ou erro na execução de um plano de ação como pretendido, apresentam um caráter multifatorial, determinadas como a lógica da cascata, facilmente compreendida pela teoria de queijo suíço (REASON, 2000), onde a ocorrência de um evento adverso ou danos a um doente pressupõe o alinhamento de vários buracos, ou seja, são sucessões de erros na estrutura ou no processo (SOUSA, 2006).

Uma das alternativas propostas para a melhoria da segurança seria apresentar sistemas de saúde com pronto acesso a informações que suportam aprender com a experiência, com a intenção de evitar com que o impacto dos erros seja mitigado. Em contraste com a " cultura patológica ", em que o fracasso é punido ou ocultado e as pessoas se recusam a reconhecer que existem problemas. Uma cultura de segurança positiva reconhece o erro inevitável e busca, de forma proativa, identificar ameaças latentes (NIEVA; SORRA, 2003) e estabelece um link entre a cultura da segurança e os resultados da assistência prestada ao paciente (NIEVA; SORRA, 2003; COLLA et al., 2005).

O maior desafio de uma organização de saúde, em se obter um sistema seguro para os seus pacientes, está na mudança cultural. A cultura da culpa individual, em que os erros são tratados como fracassos pessoais, deveria ser substituída por oportunidades para melhoria do sistema evitando os danos (IOM, 2001). Frente a isso, percebe-se a necessidade de trabalhar o desenvolvimento da cultura da segurança do paciente através dos diferentes níveis de maturidade da cultura da segurança. Para transformar as organizações nesse caminho, não há solução rápida, o tempo é prolongado e exige muito empenho, mas os benefícios poderão ser consideráveis para pacientes e profissionais (KIRK et al., 2007).

\subsection{Cultura de Segurança na Unidade de Terapia Intensiva}

As Unidades de Terapia Intensiva (UTI) são ambientes complexos e dinâmicos (BUCKLEY et al., 1997) e necessitam de tecnologia de alto nível e profissionais multidisciplinares competentes para lidar com as dificuldades do suporte avançado de vida nos pacientes gravemente enfermos. Portanto, a assistência ao paciente na UTI requer grandes avanços na formação de pessoal e uma gama de dispositivos para monitoramento contínuo e diário (BASSUNI; 
BAYOUMI, 2015; WINTERS; DORMAN, 2006).

Essas unidades foram criadas com capacidade de salvar vidas de pacientes com doenças eminentemente ameaçadoras, mas também tem o potencial de gerar um alto risco de iatrogenias (WINTERS; DORMAN, 2006). Presume-se que inúmeros pacientes hospitalizados sejam prejudicados anualmente e que grande parte desse dano ocorra na UTI (BUCKLEY et al., 1997; BECCARIA et al., 2009). Foi demonstrado numa investigação na área da saúde que os pacientes, frequentemente, sofrem erros médicos evitáveis (VINCENT, 2006).

Os pacientes críticos são mais vulneráveis a eventos adversos e iatrogenias por necessitarem de elevada técnica no pronto atendimento ao suporte de vida, nas administrações de drogas e fluidos e, nos cuidados de rotina, pois, geralmente, apresentam tanto as comorbidades quanto disfunções orgânicas agudas (BUCKLEY et al., 1997). Portanto, os cuidados intensivos apresentam substancial desafio na segurança do paciente, uma vez que requerem tomada de decisões urgentes de alto risco, baseadas nos achados clínicos com informações históricas incompletas e por médicos com diferentes níveis de treinamento (BECKAMANN et al., 2003). Esses fatores favorecem a considerável morbimortalidade atribuível aos incidentes (BUCKLEY et al., 1997), devido às relações cada vez mais imbricadas de todos estes elementos (CHANG; MULTZ; HALL, 2005; ROTHSCHILD et al., 2005; BECKAMANN et al., 2003). E resultam em um custo financeiro elevado em termos de internações hospitalares prolongadas e despesas processuais (VINCENT, 2006).

A segurança do paciente, nos últimos anos, tornou-se o foco principal para aprimorar a qualidade da saúde, devido às crescentes evidências de danos aos pacientes (WINTERS; DORMAN, 2006). A Organização Mundial de Saúde (OMS) definiu a segurança do paciente como a ausência de dano evitável a um paciente durante o processo de cuidados de saúde (WHO, 2012). Portanto, para minimizar os possíveis erros e proporcionar serviços de alta qualidade, é prioridade estabelecer uma conveniente estratégia de segurança do paciente pela gestão hospitalar, bem como a compreensão dos sistemas ao nível de administração, supervisão, designers de equipamentos, desempenho individual e o investimento na equipe de trabalho (capacitação para identificar e eliminar os riscos, treinamento para uso dos equipamentos, programa de formação profissional, avaliações das habilidades de comunicação e compatível carga horária de trabalho) (COOK; WOODS, 1994; BASSUNI; BAYOUMI, 2015; GARROUSTE-ORGEAS, M. et al., 2008; WIENER; KANKI; HELMREICH, 1993). A identificação dos erros da equipe de saúde serve como indicador de risco de iatrogenia, sendo crucial para fins de prevenção (GARROUSTE-ORGEAS, M. et al., 2010).

Algumas medidas devem ser trabalhadas a fim de melhorar a qualidade da segurança do paciente, como a compreensão dos sistemas ao nível de administração, supervisão, designers de equipamentos e do desempenho individual do funcionário relacionado aos cuidados (COOK; WOODS, 1994).

Entre os fatores de melhoria da segurança pode se destacar 0 aperfeiçoamento dos intensivistas, deixando de ser meros plantonistas e se tornando especialistas no manejo de pacientes criticamente enfermos, devido à complexidade das doenças e modalidades disponíveis para o seu tratamento (WINTERS; DORMAN, 2006).

Alguns estudos demonstraram que o emprego de especialistas diaristas, foi a intervenção de maior avanço na qualidade da saúde, com importantes reduções no risco de mortalidade na UTI (PRONOVOST et al.,2002; VAN DEN BERGHE et al., 2001; PRONOVOST et al., 2004). Infelizmente, a incapacidade de fornecer médicos 
suficientes com conhecimentos suficientes para atender um modelo de alta intensidade deixa uma grande lacuna na segurança e qualidade dos cuidados dos pacientes (EWART et al., 2004; WINTERS; DORMAN, 2006).

Um aspecto relevante, neste cenário de alto risco, que tem motivado investigações pelos resultados de incidentes com grandes perdas de vida, assim como, na aviação e energia nuclear, tem sido a má comunicação entre os membros da equipe (WIENER; KANKI; HELMREICH, 1993; WRIGHT et al., 1991). Foi observado que as relações entre comunicação e segurança nas UTI, diferentemente das indústrias de alto risco, estão aquém da compreensão das interações dos membros da equipe sob condições normais e de estresse operacionais (LEONARD; GRAHAM; BONACUM, 2004).

\subsection{Avaliação da Cultura de Segurança}

Nos últimos anos, ressaltam-se os avanços no conhecimento dentro da indústria para garantir a segurança geral, motivadas pelo conhecimento de que as principais causas de acidentes são os fatores organizacionais, gerenciais e humanos, contrário ao que se acreditava sobre as falhas técnicas.

As definições de cultura de segurança são muitos amplas, o que aventa a necessidade de mensurar os dados disponíveis (COX; COX, 1991), esclarecendo as semelhanças das culturas em uma organização (SCHEIN, 1990). Portanto, o produto da construção da cultura de segurança requer precisão, com ênfase estreita sobre o clima de segurança (atitudes e percepções) objetivado através de inquéritos por questionários (ZOHAR, 1980), entrevistas, grupos focais e técnicas projetivas (COOPER, 2000).

O setor de saúde, por envolver elevados índices de morbimortalidade, é considerado uma organização de alto risco (COLLA et al., 2005). Foi então, recomendado pelo IOM (1999), que as organizações de saúde aprimorem os estudos para uma segurança satisfatória. Havendo grande interesse em criar uma cultura que suporta a segurança do paciente, vários esforços têm sido feitos para desenvolver formas de mensurar a cultura de segurança em áreas clínicas (PRONOVOST et al., 2006).

Os questionários avaliam as atitudes e percepções, fornecendo informações satisfatórias às questões de segurança dos funcionários com as taxas de acidentes de trabalho. Os fatores comportamentais podem ser avaliados através de estudos observacionais e as interferências ambientais através de auditorias, análise da política organizacional e a análise da documentação da instituição (COOPER, 2000)

Surgiram, nos últimos anos, nove questionários para serem usados em diferentes tipos de configurações, sendo: cinco para a avaliação geral do clima de segurança do paciente nos serviços de saúde (Strategies for Leadership (SLOAPS); Patient Safety Cultures in Healthcare (PSCHO); Veterans Administration Patient Safety Culture Questionnaire (VHA PSCQ); Hospital Survey on Patient Safety (HSOPS), Culture of Safety Survey (CSS)), dois para dentro de unidades hospitalares (Safety Attitudes Questionnaire (SAQ); Safety Climate Survey (SCS)), e dois para uso em locais de cuidados de saúde específicos como setor de farmácia (Medication Safety Self Assessment (MSSA)) e de transfusão (Hospital Transfusion Service Safety Culture survey (HTSSCS)). Essas pesquisas têm sido utilizadas, principalmente, para comparações dentro e entre instituições, e as atitudes dos entrevistados sobre diversos aspectos da segurança do paciente são medidas através da escala de Likert de 5 pontos (COLLA et al., 2005). 
Sete questionários foram projetados para serem preenchidos individualmente pelos participantes, enquanto os outros dois dependem de preenchimento conjunto entre as equipes de trabalho (SLOAPS e MSSA). O SAQ, SCS e o PSCHO têm sido utilizados para comparar o clima de segurança em um ambiente de saúde com aquela do setor de aviação e aviação naval (SEXTON; THOMAS, 2004; PRONOVOST et al., 2003; GABA et al., 2003).

Os dois questionários com melhores propriedades para avaliar associações entre os escores de clima de segurança do paciente e os indicadores associados com os melhores resultados dos pacientes foram o SAQ e o CSS, sendo o último desfavorável à utilização prática (WEINGART et al, 2004).

O SAQ foi o único questionário que demonstrou relação entre os escores de clima de segurança e os resultados favoráveis dos pacientes, quanto ao menor: tempo de internação, erros de medicação, taxas de pneumonia associadas à ventilação mecânica, taxas de infecção da corrente sanguínea (SEXTON et al., 2006) e taxas de mortalidade (SEXTON, 2002).

Esse instrumento projetado para medir cultura de segurança, tanto em nível individual como em grupo (PRONOVOST; SEXTON, 2005), foi considerado uma excelente ferramenta para avaliar incidência de eventos adversos no paciente através das falhas potenciais de risco e fatores conducentes, ou seja, de situações onde não estão evidentes as chances de danos ao paciente (THOMAS; SEXTON; HELMREICH, 2003).

\section{CONSIDERAÇÕES FINAIS}

A abordagem da cultura de segurança, na área da saúde e, principalmente, na UTI, representa uma valiosa aprendizagem na identificação de atitudes e comportamentos dos profissionais de saúde em relação à segurança do paciente. Por isso, aprimorar a cultura de segurança do paciente tornou-se a base nos cuidados de saúde e foco de pesquisa.

Contudo, ressalta-se que as UTIs são ambientes complexos compostos por tecnologia e medicamentos especializados, equipe multidisciplinar com características pluricultural; funcionamento com sobrecarga de trabalho e sob pressão; e lida com pacientes de elevada gravidade e risco de vida. A interação desses fatores pode provocar falhas nos cuidados, com consequências graves para a segurança do paciente na UTI.

As falhas nos cuidados relacionados à saúde na UTI são frequentes e necessitam de manuseio apropriado através da sistemática de reconhecimento, relatório, análises e interpretação, seguido por uma cultura de aprendizagem, a partir desses erros, com resolução dos problemas de comunicação interprofissionais.

A otimização dessa cultura de segurança do paciente dentro de uma instituição assegura um ambiente de proteção, fundamental para prevenir eventos adversos. Sendo assim, imprescindível a participação nas atitudes de segurança dos profissionais que lidam diretamente com os pacientes, colaborando com os gestores das instituições de saúde nas modificações necessárias para melhorar a segurança do paciente.

A cultura de segurança do paciente depende de atuações amplas e esforços complexos nos vários segmentos de uma organização, promovendo a melhoria do ambiente e gerenciamento de riscos para uma boa prática das atividades diárias, detecção e controle nas áreas de maior impacto nos problemas de segurança, aproveitamento adequado da tecnologia e capacitação dos profissionais. 


\begin{abstract}
Patient safety aroused much concern and alert the world, after scientific evidence of high mortality rates related to a failure to provide health-related care. The complexity of the system involving the health care, particularly in hospitals, requires a health management specialized and focused on quality and patient safety. It was observed that the safety culture reflects essentially the attitudes of managers and workers and the values related to risk management and security. Until recently, studies on the safety culture were focused mainly on the exploitation of these deficiencies in the organization, communication and personal skills, with few studies demonstrating the relationship between security attitudes and performance of the team or the understanding of values, beliefs and norms an organization or, as attitudes and behaviors related to patient safety are supported, rewarded and expected. Among the peculiarities of safety culture is the need to commit to the discussion and learning from mistakes, visas are inevitable. Therefore, it is essential to identify proactively latent threats in the information and analysis of adverse events, incorporating nonpunitive rules and areas of identification measures more or less need for improved patient safety awareness. The aim of this study was to review safety culture related to health care.
\end{abstract}

Keywords: Culture, Security Management, Security 


\section{Referências}

ANVISA (Agência Nacional de Vigilância Sanitária, Brazilian Health Surveillance Agency). RDC 36/2013 Assistência Segura: Uma Reflexão Teórica Aplicada à Prática, 2013. http://www20.anvisa.gov.br/segurancadopaciente. Acesso em Jan. 2016.

AGENCY FOR HEALTHCARE RESEARCH AND QUALITY (AHRQ). Preliminary Comparative Results: Nursing Home Patient Safety Culture. 2008. http://www.ahrq.gov/qual/nhsurvey08/nhprelim08.htm. Acesso em Jan. 2016.

BASSUNI, E.M.; BAYOUMI, M.M. Improvement Critical Care Patient Safety: Using Nursing Staff Development Strategies, At Saudi Arabia. Global Journal of Health Science, v. 7, n. 2, p. 335-343, 2015.

BECCARIA, L.M.; PEREIRA, R.A.M.; CONTRIN, L.M.; LOBO, S.M.A.; TRAJANO, D.H.L. Eventos adversos na assistência de enfermagem em uma unidade de terapia intensiva. Revista Brasileira de Terapia Intensiva, v. 21, n. 3, p. 276-282, 2009.

BECKAMANN, U.; BOHRINGER, C.; CARLESS, R.; GILLIES, D.M.; RUNCIMAN, W.B.; WU, A.W.; PRONOVOST, P. Evaluation of two methods for quality improvement in intensive care: Facilitated incident monitoring and retrospective medical chart review. Critical Care Medicine, v. 31, n. 4, p. 1006-1011, 2003.

BOGNÁR, A; BARACH, P.; JOHNSON, J.K.; DUNCAN, R.C.; BIRNBACH, D.; WOODS, D.; HOLL, J.L.; BACHA, E.A.. Errors and the Burden of Errors: Attitudes, Perceptions, and the Culture of Safety in Pediatric Cardiac Surgical Teams. The Annals of Thoracic Surgery, v.85, n. 4, p. 1374-1381, 2008.

BUCKLEY, T.A.; SHORT, T.G.; ROWBOTTOM, Y. M.; OH, T.E. Critical incident reporting in the intensive care unit. Anesthesia, v. 52, p. 403-409, 1997.

CHANG, S.Y.; MULTZ, A.S.; HALL, J.B. Critical care organization. Critical Care Clinics, v. 21, n. 1, p. 43-53, 2005.

COLLA, J.; BRACKEN, A.; KINNEY, L.; WEEKS, W. Measuring patient safety climate: a review of surveys. Quality and Safety in Health Care, v. 14, n. 1, p. 364-366, 2005.

COOK, R.; WOODS, D. Operating at the sharp end: The complexity of human error. In: Human Error in Medicine. Bogner MS (Ed). Hillsdale, NJ, Lawrence Erlbaum Associates, p. 255-310, 1994.

COOPER, M.D. Towards a model of safety culture. Safety Science, v. 36, n. 2, p. 111-136, 2000.

COX, S.; COX, T. The structure of employee attitudes to safety: A European example. Work \& Stress, v. 5, n. 1, p. 93-104, 1991.

EWART, G.W.; MARCUS, L.; GABA, M.M.; BRADNER, R.H.; MEDINA, J.L.; CHANDLER, E.B.. The critical care medicine crisis: a call for federal action: a white paper from the critical care professional societies. Chest, v. 125, n. 4, p. 1518-1521, 
2004.

FENG, X., BOBAY, K., WEISS, M. Patient safety culture in nursing: a dimensional concept analysis. Journal of Advanced Nursing, v. 63, n. 3, p. 310-319, 2008.

GABA, D.M.; SINGER, S.; SINAIKO, A. et al. Differences in safety climate between hospital personnel and naval aviators. Human Factors, v. 45, n. 1, p. 173-185, 2003.

GARROUSTE-ORGEAS, M. et al. Selected medical errors in the intensive care unit: results of the IATROREF: parts I and II. American Journal of respiratory and critical care medicine, v. 181, n. 2, p. 134-142, 2010.

GERSHON, R.; STONE, P.; BAKKEN, S.; LARSON, E. Measurement of organizational culture and climate in healthcare. Journal of Nursing Research, v. 34, n. 1, p. 33-40, 2004.

HUANG, D.T.; CLERMONT, G.; LAN KONG; WEISSFELD, L.A.; SEXTON, J.B.; ROWAN, K.M.; ANGUS, D.C.. Intensive care unit safety culture and outcomes: a US multicenter study. International Journal for Quality in Health Care, v. 22, n. 3, p. 151-161, 2010.

IAEA. Safety Culture (International Safety Advisory Group, Safety-Series 75-INSAG4). International Atomic Energy Agency, Vienna, 1991.

IOM (Institute of Medicine). Crossing the Quality Chasm: A New Health System for the $21^{\text {st }}$ Century. Washington, DC: The National Academies Press, 2001.

KIRK, S.; PARKER, D.; CLARIDGE, T.; ESMAIL, A.; MARSHALL, M. Patient safety culture in primary care- developing a theoretical framework for practical us. Quality \& Safety In Health Care, v. 16, n. 4, p. 313-320, $2007 . \quad$ doi: 10.1136/qshc.2006.018366.

KLINE, T.J., WILLNESS, C., GHALI, W.A. Determinants of adverse events in hospitals-the potential role of patient safety culture. Journal of Healthcare Quality, v. 30 , n. 1, p. 11-17, 2008.

KOHN, L.Y.; CORRIGAN, J.M.; DONALDSON, M.S. Committee on Quality of Health Care in America. To err is human: Building a Safer Health System. Washington DC: National Academy Press: Washington, DC, 1999.

LEONARD, M.; GRAHAM, S.; BONACUM, D. The human factor: the critical importance of effective teamwork and communication in providing safe care. Quality and Safety in Health Care, v. 13, n. 1, p. 85-90, 2004.

NIEVA, V.F.; SORRA, J.S. Safety culture assessment: a tool for improving patient safety in healthcare organizations. Quality and Safety in Health Care, v. 12, p. 1723, 2003.

PITTET, D.; DONALDSON, L. Clean Care is Safer Care: the first global challenge of the WHO world alliance for patient safety. American Journal of Infection Control, v. 33, n. 11, p. 476-479, 2005. 
PRONOVOST, PJ; ANGUS, D.C.; DORMAN, T.; ROBINSON, K.A.; DREMISOZOV, T.T.; YOUNG, T.L. Physician Staffing Patterns and Clinical Outcomes in Critically III Patients: A Systematic Review. Journal of the American Medical Association, v. 288, n. 17, p.2151-2162, 2002.

PRONOVOST, P.J.; WEAST, B.; HOLZMUELLER, C.G.; ROSENSTEIN, B.J.; KIDWELL, R.P.; HALLER, K.B.; et al.. Evaluation of the culture of safety: survey of clinicians and managers in an academic medical center. Quality and Safety in Health Care, v. 12, n. 6, p. 405-410, 2003.

PRONOVOST, P.J.; NEEDHAM, D.M.; WATERS, H.; BIRKMEYER, C.M.; CALINAWAN, Jr.; BIRKMEYER, J.D.; DORMAN, T.. Intensive care unit physician staffing: financial modeling of the Leapfrog standard. Critical Care Medicine, v. 32, n. 6 , p. 1406-1408, 2004.

PRONOVOST, P.J; SEXTON, J.B. "Assessing safety culture: guidelines and recommendations", Quality and Safety in Health Care, v. 14, n. 4, p. 231-233, 2005.

PRONOVOST, P.J.; BERENHOLTZ, S.M.; GOESCHEL, C.A.; NEEDHAM, D.M.; SEXTON, J.B.; THOMPSON, D.A., et al.: Creating High Reliability in Health Care Organizations. Health Services Research, v. 41, n. 4p2, p. 1599-1617, 2006.

REASON, J. Understanding adverse events Human factors. In: Clinical Risk Management Edited by: Vincent CA. British Medical Journal Publications; 1995.

REASON, J. Managing the risks of organizational accidents. Ashgate Publishing, Aldershot; 1997.

REASON, J. Human error: models and management. The Western Journal of Medicine, v. 172, n. 6, p. 393, 2000.

ROTHSCHILD, J.M.; KEOHANE, C.A.; COOK, E.F.; ORAV, E.J.; BURDICK, E.; THOMPSON, S.; HAYES, J.; BATES, D.W.. A controlled trial of smart infusion pumps to improve medication safety in critically ill patients. Critical Care Medicine, v. 33, n. 3, p. 533-540, 2005.

RUNCIMAN, W.; HIBBERT, P.; THOMSON, R.; VAN DER SCHAAF, T.; SHERMAN, H.; LEWALLE, P. Towards an International Classification for Patient Safety: key concepts and terms. International Journal for Quality in Health Care, v. 21, n. 1, p. 18-26, 2009.

SCOTT-FINDLAY. S.; ESTABROOKS, C.A. Mapping the organizational culture research in nursing: a literature review. Journal of Advanced Nursing, v. 56, n. 5, p. 498-513, 2006.

SCHEIN, E.H. Organizational culture. American Psychologist, v. 45, n. 1, p. 109119, 1990.

SEXTON, J.B.: A Matter of life or death: Social psychological and organizational factors related to patient outcomes in the intensive care unit. In Unpublished doctoral dissertation The University of Texas at Austin; 2002. 
SEXTON, J.B.; THOMAS, E.J. Measurement: Assessing Safety Culture. In: Leonard M, Frankel A, Simmonds T (eds). Achieving Safe and Reliable Healthcare: Strategies and Solutions. Chicago, IL: Health Administration Press, 2004, pp. 115-27.

SEXTON, J.B.; HELMREICH, R.L.; NEILANDS, T.B.; ROWAN, K.; VELLA, K.; BOYDEN, J.; ROBERTS, P.R.; THOMAS, E.J.. The safety attitudes questionnaire: psychometric properties, benchmarking data, and emerging research. BMC Health Services Research, v. 6, p. 44, 2006. doi:10.1186/1472-6963 Disponível em: www.biomedcentral.com/1472-6963/6/44. Acesso em jan. 2016.

SOUSA, P. Patient safety- A necessidade de uma Estratégia Nacional. Acta Médica Portuguesa, v. 19, n. 5, p. 309-318, 2006.

SORRA, J.; NIEVA, V.F. Hospital Survey on Patient Safety Culture (AHRQ publication No 04-0041) Rockville, MD: Agency for Healthcare Research and Quality; 2004. Disponível em: http://www.ahrq.gov/qual/hospculture/hospcult.pdf. Acesso em jan. 2016.

TEIXEIRA, T.C.A.; CASSIANI, S.H.B. Análise de causa raiz: avaliação de erros de medicação em um hospital universitário. Revista da Escola de Enfermagem da USP, v. 44, n. 1, p. 137-144, 2010.

THOMAS, E.J.; SEXTON, J.B.; HELMREICH, R.L. Discrepant attitudes about teamwork among critical care nurses and physicians. Critical Care Medicine, v. 31, n. 3, p. 956-959, 2003.

VAN DEN BERGHE, G.; WOUTERS, P.; WEEKERS, F.; VERWAEST, C.; BRUYNINCKX, F.; SCHETZ, M.; VLASSELAERS, D.; FERDINANDE, P.; LAUWERS, P.; BOUILLON, R.. Intensive insulin therapy in critically ill patients. The New England Journal Medicine, v. 345, n. 19, p. 1359-1367, 2001.

VINCENT, C.; TAYLOR-ADAMS, S.; STANHOPE, N. Framework for analyzing risk and safety in clinical medicine. British Medical Journal, v. 316, n. 1, p. 1154-1157, 1998.

VINCENT, C. Understanding and responding to adverse events. The New England Journal of Medicine, v. 348, n. 11, p. 1051-1056, 2003.

VINCENT, C. Patient Safety. London: Elsevier, 2006.

VINCENT, C. Patient Safety. Second edition. Wiley-Blackwell, Chichester, 2010.

WACHTER, R.M. Compreendendo a segurança do paciente. Porto Alegre: Artmed, 2010.

WEINGART, S.N.; FARBSTEIN, K.; DAVIS, R.B.; PHILLIPS, R.S. Using a multihospital survey to examine the safety culture. The Joint Commission Journal on Quality and Patient Safety, v. 30, n. 1, p. 125-132, 2004.

WIENER, E.L.; KANKI, B.G.; HELMREICH, R.L. Cockpit resource management. San Diego, CA, US: Academic Press: p. Xxi 519, 1993. 
WIEGMANN, D.A.; ZHANG, H.; von THADEN, T.L.; SHARMA, G.; GIBBONS, A.M. A Synthesis of Safety Culture and Safety Climate Research. University of Illinois Aviation Research Lab Technical Report ARL-02-03/FAA-02-2, 2002.

WIEGMANN, D.A.; ZHANG, H.; von THADEN, T.L.; SHARMA, G.; GIBBONS, A.M. Safety Culture: An Integrative Review. The International Journal of Aviation Psychology, v. 14, n. 2, p. 117-134, 2004.

WHO. World Alliance for Patient Safety: Forward Programmed. Geneva: WHO; 2004, p. 1-27.

WHO. World Healthcare Organization. The second global patient safety challenge: safe surgery saves lives. WHO guidelines for safe surgery, 2009.

WHO. Patient Safety Program, 2012 Disponível em: http://www.who.int/patientsafety/campaigns/en/ Acesso em jan. 2016.

WINTERS, B.; DORMAN, T. Patient-safety and quality initiatives in the intensive care unit. Current Opinion in Anesthesiology, v. 19, n. 1, p. 140-145, 2006.

WOLFE, A. Institute of Medicine Report: Crossing the Quality Chasm: A New Health System for the 21st century. Policy Politics Nursing Practice, v. 2, n. 3, p. 233-235, 2001.

WRIGHT, D.; MACKENZIE, M.; BUCHAN, I.; CAIRNS, C.S.; PRICE, L.E. Critical incidents in the intensive therapy unit. The Lancet, v. 338, n. 8768, p. 676-681, 1991.

ZAMBON, L.S; DAUD-GALLOTTI, R.; NOVAES, H.M.D. Introdução à Segurança do Paciente, 2010. Disponível em: <http://pesquisa.proqualis.net/resources/000000484>. Acesso em: jan. 2016.

ZOHAR, D. Safety climate in industrial organizations: theoretical and applied implications. Journal of Applied Psychology, v. 65, n. 1, p. 96-102, 1980. 